\title{
Michał Wróblewski, Medykalizacja nadpobudliwości. Od globalnego standardu do peryferyjnych praktyk [Eng. Medicalisation of hyperactivity. From global standard to peripheral practices], Kraków: Universitas 2018, pp.332, ISBN 97883-242-3479-0
}

Anna Witeska-Młynarczyk

Institute of Ethnology and Cultural Anthropology, The University of Warsaw

Does $\mathrm{ADHD}^{1}$ really exist? Michał Wróblewski, a sociologist and philosopher from the Nicolaus Copernicus University in Torun, argues that it does. During the course of his 300-plus page new book, he explains in a precise, interesting and erudite way, the phenomenon of this relatively young diagnostic term used in the psychiatry of children and youth worldwide. He writes about the global and local history of ADHD with a great deal of detail and thoughtfully discusses both the scientific and social controversies surrounding this disorder while emphasising their dynamics and complexity. The author guides the reader towards his own ethically considered position on hyperactivity and explains how and why ADHD exists in the modern world.

The book is a sociological analysis of the medicalisation of ADHD carried out from the global level and with particular emphasis on the American context. It also presents other national contexts, e.g. German, French, Italian, and Polish - where the author conducted his own qualitative research: in-depth interviews with experts and analysis of the discourse of Polish media and the content of internet forums. Medicalisation of hyperactivity... (Pol. Medykalizacja nadpobudliwości...) is not a book critical of contemporary psychiatry. I would instead argue that the author attempts to explain the mechanism. Wróblewski has written a very strong, coherent monograph based on complex and ambitious theoretical inspirations that give this work a prudent language that is free from judgment, but also which provides methodological rigor by which $\mathrm{ADHD}$ - a phenomenon that is heterogeneous and in a continuous process of becoming - is presented as logical and tangible, although far from simple.

The book consists of an introduction, five chapters and a conclusion. In the introduction, the author provides readers with the main trends in the theory of

I ADHD - Attention Deficit Hyperactivity Disorder is a psychiatric diagnostic category known also under the label Hyperkinetic Disorder. It involves symptoms of hyperactivity, inattention and impulsivity and it is diagnosed both in children and in adults. 
social sciences, which he incorporated in the research. The theoretical approach developed by Wróblewski combines the sociology of medicine (in particular, a new theory of medicalisation, which departs from a simple idea of medicine as an instrument of top-down social control), medical anthropology (by discussing such concepts as illness, disease and sickness), sociology of medical knowledge (in particular, the approach to a disease as a social fact), actor-network theory (ANT) and bio-political analyses (the author uses Immanuel Wallerstein's centre-periphery model and refers to Michel Foucault's reflection on deviation and biopower). The author discusses, for example, Peter Conrad's theory of medication as well as Adele Clarke's theory, and briefly presents case studies in the field of sociology of medicine, health and illness, such as the works of Ian Hacking on dissociative identity disorder or Allan Horwitz on depression. The author also discusses texts by Ludwik Fleck and Ian Hacking in the field of sociology of medical knowledge and explains such concepts as "the collective knowledge production", "creation and development of a scientific fact", and "ecological niches". In the final part of the introduction, the author convincingly presents a rationale for choosing the methodology of his research project.

In the subsequent chapters Wróblewski expands on the content outlined in the introduction. The first chapter is devoted to the topic of medicalisation. The author introduces the classic theory of medicalisation, critiques it, introduces a more nuanced picture of modern medicine and shows its connections with technoscience, and in particular, with neuroscience. The sociologist also places his analysis in a historical and economic context and devotes space for a discussion regarding the economic changes resulting from the progressive neoliberalism and commercialisation of medical services and the commodification of health, including activities undertaken by non-state actors such as pharmaceutical companies. Wróblewski also discusses the subject of state bio-politics and new ways of disciplining oneself, which are expressed, for example, in the ideology of healthism. The topic of "bio-sociality" and the impact of patient movements on the processes of medicalisation are also important for the case study. In the first chapter, the author provides a heterogeneous image of medicalisation, which is developed in the following parts as a more concrete content, because it concerns only one disorder and its functioning in the Polish context.

The second chapter is devoted to the history of $\mathrm{ADHD}$ as a medical fact. Wróblewski considers the objectification processes of this diagnostic term on three levels: development of medical knowledge (discovery of disorder and gathering empirical knowledge), the evolution of psychiatric discourse, and, finally non-medical factors that had a formative influence on the socialisation of the diagnostic term in question, such as development of civil society, the impact of large capital, and state policies. The sociologist takes us on a journey in which we see how, over time, with the help of many institutions and channels for disseminating knowledge, $\mathrm{ADHD}$ has become a recognisable social problem. 
Wróblewski's book, and in particular the third chapter, deals with the globalisation of the biomedical model of disorders. The author shows the process of transferring and expanding the impact of biomedical infrastructure in two dimensions - impacts on institutions and medical practice and on the culturally defined image of health and disease. The sociologist argues that "the globalisation of ADHD is connected, on the one hand, with the globalisation of neoliberal rules of social life, which generate specific attitudes and problems, and on the other, with the globalisation of expert systems that are to remedy these problems" (Wróblewski 2018, I52). What is both interesting and important is the discussion on the use and reliability of epidemiological data, undertaken by, for example, China Mills in her works, and a reflection on psychiatric diagnostic technology and its spread. These and other tools for making ADHD real in local contexts are discussed by the author with high accuracy and with a focus on practice and materiality. The globalisation of mental disorders has different trajectories. As the author writes,

"it is not a one-dimensional and one-way process. [...] It may give rise to resistance and controversy, which in the longer term will make the local vision of the disorder specific" (Wróblewski 20I8, I6I).

The last two chapters of the book present the Polish context. The fourth chapter is devoted to medical practice. Assuming that ADHD is a border object (that is, for which various expert groups take different points of view, while cooperating to stabilise this object), the author shows how physicians and psychologists cope with diagnostic ambivalence and the heterogeneity of diagnostic and therapeutic practices. Based on the statements of experts, the chapter concludes that in Poland the mixed mode of understanding ADHD prevails, assuming that the biological factor is important in the aetiology of the disorder, but that social issues are also significant. This is an important conclusion, because it opens the way to include conclusions about the specificity of the Polish context for analyses comparing ways of constituting ADHD in different national contexts.

Finally, the fifth chapter discusses the evolution of the media discourse on ADHD in Poland and sheds light on the struggles of parents with controversy and uncertainty by presenting discussions on internet forums. Wróblewski identifies these areas of production and learning as a "lay level" ["poziom potoczny"]. He tries to link narratives to the broader questions and issues discussed in previous chapters, for example, by looking for an answer to the question of how medical rationality is established in the world of laypeople. Thanks to the inclusion of material from his own research, the book becomes something more than a description of actors and networks, a story about the evolution of the definition of a disorder or the analysis of emerging controversies. The words of doctors, educators, psychologists and parents cited in the pages of the book and anchored in actually lived reality, describe to a certain extent how ADHD is being established in (not only) medical practice in modern Poland. The analysis of the 
content of online forums for parents of children with ADHD, shows how demanding the role of caregivers is. The author also points to the important role of biosociality in legitimising and stabilising the biopsychiatric framework and in solving controversies, which are quite common for ADHD.

The question of whether ADHD really exists becomes a theoretical question for Michał Wróblewski. In the conclusion, there are echoes of the dispute between constructivism and realism in trying to provide the answer to this question. He reaches for, among others, the actor-network theory, which focuses on practices and processuality and encompasses both biologicality and materiality, as well as the dynamics of social practices and their political position. Wróblewski's book is an expression of the process of departing from the division into disease and illness and simple models of medicalisation in Polish works in the field of social sciences focusing on health and disease, in favour of perspectives that are processual and focused on internment practices anchored in the historical and material world. The methodology used by the author does not privilege the practices themselves, but only allows for looking at different kinds of narratives about them. Nonetheless, learning about the ADHD network and controversies gives the reader a very broad and fairly detailed picture of the process of formation of ADHD in Poland, understood as peripheries which, as the author writes, are doomed to "reproduce psychiatric knowledge" (Wróblewski 20I8, I48).

In his work, the author refrains from criticising the practices of medicalisation. However, the author's ethical prudence, in my opinion, leads to the drawing of an overly optimistic picture. From my research experience it appears that when we start to look at the formation of ADHD in the everyday life of Polish children, in particular children from families of modest means, it is somewhat more difficult to preserve a neutral stand towards the practices of psychiatry. From the perspective adopted by the author, there are no visible social inequalities or those resulting from the place of residence, and how they affect children's contact with psychiatry. The author does not touch on the subject of the state of Polish child psychiatry or the readiness of Polish schools to support children diagnosed with ADHD. The author only briefly refers to the subject of stigmatisation, which is key from the point of view of children's experiences with psychiatric practices. Undoubtedly, the children themselves are missing on the pages of this book. As always, they fidget in their chairs, are considered naughty and they are cases in the stories of doctors, teachers and parents - they remain the object of research. They are not treated as having agency.

In spite of these remarks, I have no doubt that the book will be a model work in Polish thought about medicalisation and it will set out ways to analyse how a mental disorder becomes a social fact. The author indicates where to look for mechanisms that make the medical term "become a full-fledged element of the social world" (Wróblewski 20I8, I9), recognises the complexity of social objectivity, and also underlines the historical dimension of the emergence of social facts. Selected fragments of the text should 
certainly be included in syllabuses in the field of medical anthropology. Although we will not find ethnographic material on the pages of the book, it should be emphasised that the text contains and patiently explains the imaginarium important for contemporary ethnography of health and disease. Anyone interested in search for an answer to the question "does / how does ADHD really exist?", should reach out for Wróblewski's book.

\section{Author's address}

Anna Witeska-Młynarczyk PhD

Institute of Ethnology and Cultural Anthropology

University of Warsaw

ul. Żurawia 4

Warsaw oo-503, POLAND

e-mail: a.witeska-mlyn@uw.edu.pl

ORCID: 0000-000I-6300-8083 
